\title{
DA GRAMÁTICA AO DISCURSO OU DO DISCURSO À GRAMÁTICA? IMPLICAÇÕES DISCURSIVAS AO ENSINO DE LÍNGUA PORTUGUESA
}

\author{
José Nildo Barbosa de Melo Junior*
}

\begin{abstract}
RESUMO: Este trabalho tem por objetivo promover algumas reflexões não apenas sobre a maneira como livros didáticos (LD) e exames vestibulares elaboram questões (perguntas) referentes a conteúdos diversos, notadamente na área de língua portuguesa, mas ainda como determinadas informações são levadas aos alunos, por meio de textos nos capítulos dos LD, e aos docentes que utilizam esses livros, na seção de orientações ao professor. A arquitetura teórica que sustenta tal discussão está alicerçada na Linguística Aplicada, imbricando-se a outros autores que tomam esse direcionamento teórico, bem como a perspectiva sociointeracionista e discursiva, no ensino de língua portuguesa, sobretudo quando abordam a relação entre ensino e aprendizagem e aspectos sociodiscursivos das práticas linguageiras. Pautamos a discussão numa abordagem qualitativa de pesquisa (FLICK, 2009), considerando que tal abordagem nos possibilita, enquanto pesquisadores, a apropriação de métodos e teorias que expliquem o fenômeno, a observação de perspectivas que servem de base para a análise do objeto teórico e reflexão acerca de questões levantadas. A análise das referidas questões permitiu constatar que diversos livros didáticos e exames vestibulares, a exemplo dos que compuseram o bojo deste estudo, não abordam práticas sociais da linguagem no ensino de língua portuguesa, priorizando apenas aspectos gramaticais e desconsiderando importantes elementos sociodiscursivos, e as orientações ao professor não apresentam uma abordagem sociodiscursiva da linguagem, a qual precisa efetivar-se no processo de ensino e aprendizagem, em consonância aos aspectos gramaticais.
\end{abstract}

PALAVRAS-CHAVE: Ensino de língua portuguesa; Exames vestibulares; Livros didáticos; Orientações ao professor; Práticas sociais da linguagem.

\section{Considerações iniciais}

Quando iniciamos nossas reflexões, do ponto de vista teórico-metodológico, e pomos à vista nossas inquietações sobre a prática da aula de português, costumamos traçar um percurso pelos caminhos por que passamos, desde estudante da educação básica, passando por nossa formação enquanto professores, até nossa prática de ensino de língua portuguesa. O recrudescimento da correção gramatical (GERALDI, 2006), dos elementos intrinsecamente linguísticos, o fator social abordado sutilmente e orientações breves de 
como abordar outros elementos imprescindíveis para tornar as aulas mais produtivas, envolventes e proveitosas fazem parte desse circuito de reflexões e me fazem repensar minhas práticas, táticas, levando em conta técnicas e metodologias já existentes e que necessitam ser (re) discutidas.

O cerne da questão a ser discutida aqui não está em localizar os responsáveis por persistirem em uma prática pedagógica que mantenha uma perspectiva reducionista do estudo da palavra, da frase descontextualizada (ANTUNES, 2003) ou do texto como mero pretexto, para atingir aspectos puramente gramaticais, por exemplo - ainda que tal problema esteja espalhado por várias instâncias, de ordem histórica, política, ideológica, cultural, didático-pedagógica, psicológica, física, situacional, cognitiva, sociocognitiva e das relações de poder que circundam por tais instâncias, e seja de responsabilidade de alguém ou de outrem, em maior ou menor grau -, mas está em refletir sobre as possibilidades de abordar tais fenômenos, sem se desvencilhar do social.

De fato, é desafiador levar às nossas salas de aula uma compreensão mais relevante do que as práticas efetivas sociais de uso da linguagem podem suscitar, no contexto escolar e fora dele, quando um ensino que exclui o viés sociodiscursivo predomina. Embora não seja o foco deste trabalho, cabe mencionar que o insucesso escolar se manifesta de várias maneiras e por diversos fatores, e uma das formas de tentar minimizar tal problema é trazer para sala de aula fenômenos da vida social que confluam para os fenômenos da língua(gem) e para uma visão que considere a linguagem como uma atividade ou forma de interação social, envolvendo nossos conhecimentos prévios (de mundo, da cultura, linguísticos, textuais, enciclopédicos) no processo de ensino e aprendizagem.

Assim, objetivamos trazer, neste trabalho, algumas reflexões sobre como livros didáticos e exames vestibulares têm construído questões (perguntas) - reforçamos, aqui, a dificuldade que a escola apresenta, ao abordar os recursos multissemióticos de gêneros discursivos multimodais - em gêneros discursivos vários, não estabelecendo interfaces importantes entre língua e cultura, povo e identidade, sujeito e identidades, língua e social, língua e interação. Ademais, temos por finalidade discutir como determinadas informações 
são levadas aos alunos, por meio de textos nos capítulos dos LD, e aos docentes que utilizam esses livros, na seção de orientações ao professor.

\section{A perspectiva discursiva da Linguística Aplicada: algumas implicações para o en- sino de língua portuguesa}

Nas salas de aula de língua portuguesa, o professor parece tratar com obviedade pormenores de conteúdos em que os alunos não encontram significado fora de sua realidade, em algo que eles não vivem (MELLO; FREIRE, 1986). Isso, possivelmente, justifique-se, como afirma Weffort (1996) pelo fato de não termos sido educados para olhar pensando o mundo, a realidade, nós mesmos, já que nosso olhar cristalizado nos estereótipos produziu em nós paralisia, fatalismo, cegueira.

Trata-se de uma questão um tanto desafiadora: refletir sobre as práticas efetivas sociais de uso da linguagem, numa perspectiva aplicada, mediadora, inter/transdisciplinar, criando inteligibilidades (MOITA LOPES, 1996; 2006) para questões linguísticas. Tal questão exige de nós reflexão de nossas práticas pedagógicas, tendo em vista a necessidade

de conjugar olhares teóricos, uma vez que a sala de aula é um ambiente plural, multifacetado, e o sujeito que nela se insere, constituído nas relações sociais.

Nesse tocante, indubitavelmente, a Linguística Aplicada (doravante LA) assume uma postura crítica e pertinente, suscitando uma reflexão sobre as concepções de língua e linguagem e considerando que, na pesquisa, a visão de linguagem pode abranger noções de sujeito, gramática, ensino, pesquisa e aprendizagem, cruciais para ressignificar questões linguísticas nas práticas sociais e, consequentemente, em nossa prática docente (SANTOS, LIMA, 2016). Não defendemos uma concepção de linguagem como instrumento de comunicação, aliada ao Estruturalismo e à Teoria da comunicação, visão que separa o homem do seu contexto social, limitando-se ao estudo do funcionamento interno da língua, mas nos orientamos na concepção de linguagem como processo de interação social (GERALDI, 1984), em que os sujeitos são dialógicos, agentes sociais e dialéticos, trocando experiências, conhecimentos, (inter)agindo. 
A linguagem é pois um lugar de interação humana, de interação comunicativa pela produção de efeitos de sentido entre interlocutores, em uma das situação de comunicação e em um contexto sócio-histórico e ideológico. Os usuários da língua ou interlocutores interagem enquanto sujeitos que ocupam lugares sociais e "falam" e "ouvem" desses lugares de acordo com formações imaginárias (imagens) que a sociedade estabeleceu para tais lugares sociais. (TRAVAGLIA, 2009, p. 23).

Santos (2007 apudSANTOS, LIMA, 2016, p. 94) reitera pontuações que concernem a esse tópico, quando pontua: “qualquer prática pedagógica não prescinde de concepções subjacentes que direcionam, determinam todo o trabalho desenvolvido". É imprescindível que o professor (supostamente quem elabora as questões de livros didáticos, vestibulares e módulos) assuma uma postura reflexiva, repensando os pressupostos teóricos, canalizados para o processo de ensino e aprendizagem, por meio de sua prática docente, adotados em nossos livros didáticos, módulos escolares e, ainda, na elaboração de questões de vestibular, evidenciando um olhar tendencioso e enviesado acerca de questões linguísticas e extralinguísticas, textuais e contextuais, excluindo a visão sociodiscursiva e sociointeracionista de tal contexto.

\section{Análise de questões de livros didáticos sob a perspectiva discursiva da LA}

Observaremos e analisaremos aqui como questões linguísticas são exploradas em algumas questões de livros didáticos que trazem um olhar reducionista acerca de temáticas abordadas em gêneros discursivos, presentes nas referidas questões, e sobre as pontuações teóricas e metodológicas trazidas nos referidos livros didáticos. A análise tomou por base as imagens 1, 2, 3 e 4 sobre as quais discorremos adiante; nesse tocante, a nossa proposta

não é criticar o uso do texto como mecanismo fomentador da aprendizagem significativa, reflexiva e crítica, mas criticar a maneira pretensiosa como os manuais trazem determinadas percepções e pontuações a respeito dos objetivos trazidos pelos LDs.

No primeiro livro didático, há a terceira parte "Redação e leitura", dispondo do capítulo 1, intitulado "Linguagens: entre textos, entre linhas" - tal capítulo traz 6 textos, de gêneros discursivos variados -, representado pela imagem 1 a seguir, em que se sugere 
a localização de elementos contextuais (locutor ou enunciador, interlocutor, suporte ou portador, objetivos/intenções/ propósitos comunicativos do enunciador/emissor do texto), acrescentados ao tema abordado, aos recursos de linguagem escolhidos pelo autor, entre aqueles disponíveis na língua, [que] determinam o tipo ou o gênero textual que precisamos produzir, verificam-se considerações teóricas que refletem o caráter enviesado, pois, quando se diz a finalidade é tornar o leitor mais atento e um produtor de textos de qualidade, descredenciam-se as habilidades de um público diverso de alunos com habilidades e dificuldades diversas.

É preciso trazer um discurso que estimule a ampliação das capacidades de que tais alunos dispõem, desenvolvendo algumas, ampliando outras, e professor, na condição de mediador e sujeito ampliador de visões de mundo, de língua, de fatos sociais, precisa se utilizar desse último discurso. Não estamos elucidando que o professor tem de ser um agente transgressor das normas sociais, já que as relações de poder interferem, notoriamente, em nossas escolhas e práticas diárias, pessoais e profissionais, mas que seja um agente que reflita junto aos alunos, trave diálogos sociais, pensando sobre as múltiplas possibilidades de atividades e ações de linguagem, as quais atuam, decisivamente, nas nossas escolhas e nas do outro.

Imagem 1 - Questão de livro didático

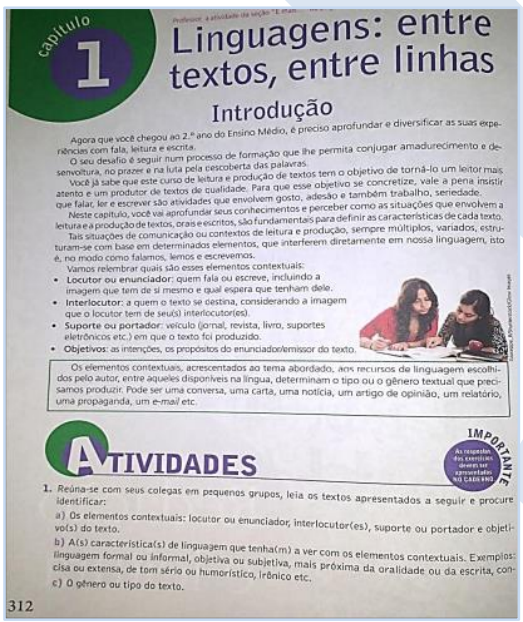

Fonte: Amaral (2013) 
O próprio discurso apresentado no início da seção já faz uso de uma modalidade assertiva/epistêmica, afirmando categoricamente o que "será alcançado", fazendo asserções sobre o fato e manifestando a validade do material, induzindo o leitor a crer que a seção mostrará a solução para o problema, comprovando o viés positivista e cartesiano, bem como marcando uma visão que objetiva doutrinar, ao dizer: "Você já sabe que este curso de leitura e produção de textos tem o objetivo de torná-lo um leitor mais atento e um produtor de textos de qualidade.” Observemos como o texto publicitário, na imagem 2, utiliza a linguagem para vender o serviço e traz um discurso engessado e cristalizado, discurso reiterado na imagem 3 , nas orientações ao professor.

Imagem 2 - Texto de livro didático para o aluno

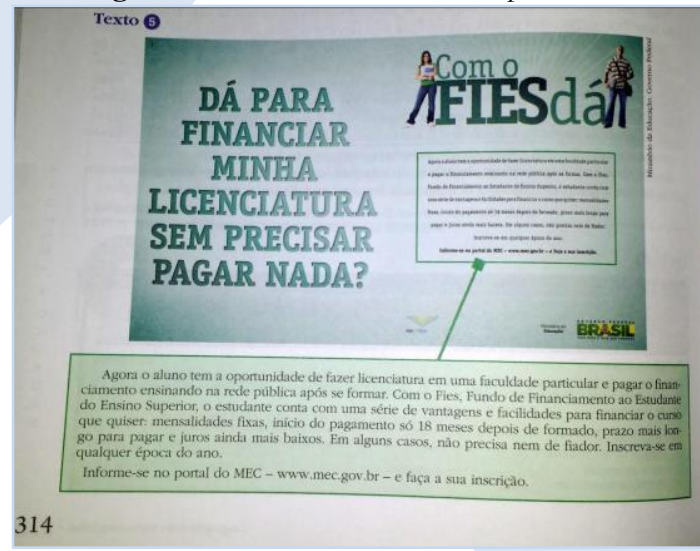

Fonte: Amaral (2013)

Na seção do livro, o professor é orientado a ver sugestões para o encaminhamento da atividade em "Conversa com o professor", antes de abordá-la em sala de aula. O que nos chamou atenção foi, exatamente, como o autor do livro didático sugeriu procedimentos para atender ao comando da questão, os quais não assumem uma postura crítica, mas tendenciosa, reducionista, conforme se verifica na imagem 3, extraída da seção "Sugestões de procedimentos e propostas de atividades complementares". 
Imagem 3 - Orientação ao professor

- Texto 5 - Chamar a atenção dos alunos para os
elementos persuasivos, isto é, que pretendem le-
vá-los a aderir à proposta da propaganda, seja nas
imagens (um rapaz e uma moça, ambos "atraen-
tes" e munidos de material escolar, índice de que
são estudiosos), seja nos textos: uma pergunta,
supostamente de um jovem ("Dá para financiar
minha licenciatura sem precisar pagar nada?"),
seguida da resposta da instituição, colocada es-
trategicamente entre os jovens, como um slogan:
"Com o FIES dá". Em letras menores, os detalhes,
que ressaltam as vantagens e facilidades prove-
nientes da adesão: mensalidades fixas, início do
pagamento só após 18 meses de formado, prazos
longos, juros baixos, possibilidade de dispensa do
fiador etc. Tais elementos são dirigidos aos interlo-
cutores visados pela propaganda: jovens da escola
pública que ambicionam cursar o Ensino Superior
e tornar-se professores, embora não tenham con-
dições de pagar os estudos numa faculdade par-
ticular. Atentar também para o uso de verbos no
modo imperativo, próprio desse gênero textual:
"Inscreva-se em qualquer época do ano. Informe-
-se no portal do MEC - http://ler.vc/htev3w - e
faça a sua inscrição".

Fonte: Amaral (2013)

Esse olhar reducionista e enviesado aponta a ideia de que jovens da escola pública ambicionam cursar o ensino superior e tornar-se professores, não havendo a possibilidade de se tornarem engenheiros, advogados, profissionais da saúde ou quaisquer outras profissões, já que o FIES, Fundo de financiamento ao estudante do ensino superior, reduz as possibilidades de alunos da rede pública vislumbrarem outras profissões a uma, ser professor, por não terem condições socioeconômicas de pagar um curso superior na rede particular. Isso, em alguma medida, diminui a importância e o lugar sociais que as licenciaturas ocupam em nosso país, dando a entender que somente alguém de classe social baixa, de status socioeconômico reduzido e sem oportunidades, tornar-se-á professor, a partir de tal financiamento; há, ainda, a visão deturpada de que estar munido de material escolar é indício de que são estudiosos, suscitando uma discussão muito mais ampla acerca do tópico 
"A educação pública de qualidade social com ênfase no acesso, na permanência e no êxito escolar", sobre quais elementos permeiam e constroem a qualidade social da educação pública.

Embora a categoria "contexto" seja posta na imagem 1, ela, comumente, desaparece em várias seções dos $\mathrm{LD}$ e de questões de vestibular, tratando de questões puramente normativas, inserindo o texto simplesmente como um instrumento de comprovação para fins gramaticais, abordando a concepção de linguagem como instrumento de comunicação, não havendo nenhum tipo de relação entre os múltiplos instrumentos semióticos, elementos verbais e não verbais, de que dispõem a charge apresentada na questão, conforme se verifica na imagem 4.

Imagem 4 - Questão de livro didático

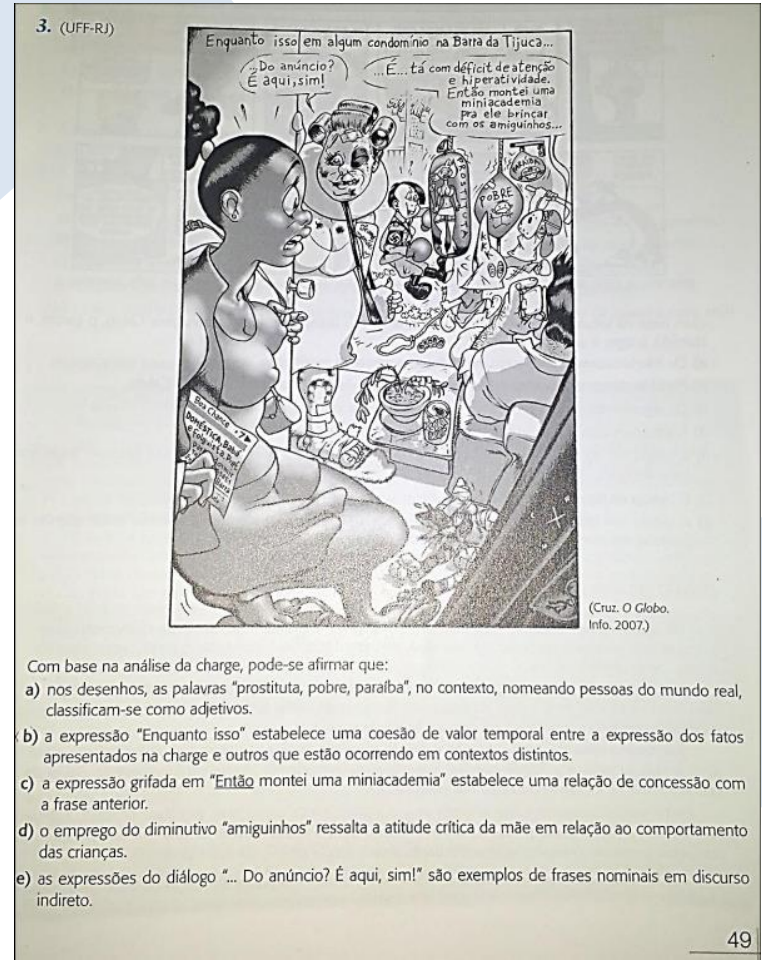

Fonte: Cereja, Magalhães e Cleto (2009) 
Não podemos sequer dizer que o gênero discursivo em foco situa-se numa prática de letramento, no sentido mais elementar do termo - para os usos sociais da escrita e por que não dizer da fala -, porque exclui o posicionamento de Moita Lopes (1998, p. 304-5), defendido por nós, quando o autor salienta, apoiando-se em vários estudiosos da linguagem: "O discurso como uma construção social é, portanto, percebido como uma forma de agir no mundo", pelo significado ser um construto negociado pelos participantes discursivos, e a construção social do significado situar-se em circunstâncias sócio-históricas particulares e ser mediada por práticas discursivas em que tais participantes se inserem (MOITA LOPES, 1998), levando-os a construir sua realidade social e a refletir sobre ela, por meio da linguagem.

Nesse sentido, o contexto e a interação discursiva, numa visão bakhtiniana e volochinoviana da palavra, mas também pragmática, possibilitam a construção de significados com o outro e permitem a contextualização ou interpretação da produção discursiva de sujeitos e de práticas sociais de uso da linguagem. A visão de LA mestiça, de natureza interdisciplinar/transdisciplinar que vislumbra "criar inteligibilidades sobre problemas sociais em que a linguagem tem um papel central' (MOITA LOPES, 2006, p. 14, itálico do autor) implica a mobilização de representações sociais sobre o mundo e os sujeitos plurais que nele se inserem e de práticas discursivas, por consequência, socialmente contextualizadas.

Esse posicionamento suscita para a compreensão e interpretação do texto, o contexto de produção (o lugar de produção, momento de produção, quem produziu, quem lerá). Suscita ainda um contexto social e subjetivo da interação comunicativa (lugar social ou formação social de que se origina o texto, posição social do emissor e do receptor, objetivo (os objetivos da interação). Faz-nos pensar acerca da "relevância social da temática e do objetivo gerais" de um fenômeno discursivo, das práticas discursivas envolvidas no fenômeno e dos possíveis efeitos de sentido produzidos, "mapear a rede semântica e a episteme em jogo, necessariamente sustentada pela multiplicidade de vozes, sistema de valoração, discursos e regimes de verdade" e "estranhar sentidos essencializados e dogmas mumificados construídos na cultura com relação ao objeto", não compactuando com uma 
visão reducionista, explicações definitivas, certezas bem alicerçadas, provas incontestáveis (FABRICIO, 2006, p. 59), o que não é verificado nas imagens 1, 2, 3 e 4.

É salutar dar ao aluno (vestibulando ou estudante) condições de compreender o gênero, consciente das condições de produção, circulação e recepção de uma charge; localizar a charge no jornal em que foi publicado (veículo, suporte, tempo, espaço etc.) e não apenas recortá-la e tirá-la de sua situação de produção, circulação e recepção; especificar a seção e o caderno em que ela aparece, comparando com outros jornais que também têm charges, refletindo junto ao aluno sobre o fato de que esse não é um texto autônomo, mas faz parte dos gêneros jornalísticos e/ou opinativos que caracterizam a imprensa contemporânea; observar junto ao aluno os demais textos que participam da página em que a charge se encontra, estabelecendo e construindo juntos - professor e alunos - as relações existentes entre os textos; analisar o conjunto das matérias publicadas no jornal, naquele dia e em anteriores/posteriores, e a maneira como a charge se relaciona com elas, nesse e nos jornais imediatamente anteriores/posteriores; é fundamental também que professor e alunos chamem atenção de, como todos os demais gêneros do jornalismo opinativo, a charge possibilitar a compreensão de um dado aspecto social, de forma diferenciada de outros gêneros, mas tendo em comum com eles o fato de refletir e refratar um acontecimento, satirizando-o ou criticando-o.

Ademais, no exemplo 4, espera-se que o comando da questão em evidência aborde não somente o aspecto gramatical, considerando o todo significativo presente no conteúdo textual e discursivo, cujo teor aponta fatores relevantes da vida social, a construção de identidades sociais - prostitutas, nordestinos e pobres - (MOITA LOPES, 1998), aspectos relacionados a estruturas minoritárias (prostitutas, pobres, nordestinos), apologia a um posicionamento nazista, ao grupo Ku Klux Klan (KKK), uma organização racista secreta que promovia atos de violência e intimidação contra imigrantes, negros, católicos, homossexuais e judeus, às relações de poder de instituições, as quais se instauram na sociedade e imprimem controle sobre o sujeito (reporta-nos aos aparelhos ideológicos de Estado), como preconizam os estudos que têm sua base nas ideologias sociais etc., fatores sociais que 
poderiam ser explorados não apenas no diálogo entre professor e alunos, mas ainda na própria questão escrita do LD e do exame vestibular.

Todavia, o comando da questão desconsiderou todo o contexto social, ideológico, histórico e político que se poderia inserir no arcabouço de conhecimento do aluno, suscitando conteúdos relevantes, conteúdo estes que, estando associados ao conhecimento linguístico trariam experiências significativas.

A crítica, aqui, tecida não aponta para o ensino da Gramática Normativa, objetivando fazer o professor se desvencilhar de questões prescritivas da língua, sobretudo, porque o ensino da competência linguística (prescritiva ou gramatical) é fundamental para o processo de letramento do aluno, mas aponta para o modo como o texto é tratado, ou melhor, não tratado, já que todas as questões sociais são esquecidas. Não estamos defendendo, aqui, a abolição do estudo prescritivo, mas a confluência de perspectivas, sobretudo, enfatizando o aspecto sociodiscursivo da linguagem, cuja evocação é, sem dúvidas, imprescindível, transcende (ultrapassa) os limites do aspecto puramente gramatical e contribui para descontruir certas visões cristalizadas.

Nesse sentido, seja na escola, seja no contexto universitário - notadamente, em cursos de licenciatura e de bacharelado que não os de Letras - as pessoas têm uma visão equivocada relacionada à inutilidade do estudo da língua(gem) ou acham que tal estudo se reduz à gramática. No entanto, o ensino de língua portuguesa deve propagar que as relações sociais, a construção (produção) de sentidos e a interação verbal (discursiva) requerem que os sujeitos ativem outros tipos de conhecimento, além do gramatical, conforme aponta Antunes (2007), quais sejam: o conhecimento do real ou do mundo, o conhecimento das normas de textualização e o conhecimento das normas sociais de uso da língua.

Como salientamos, não estamos descredenciando a posição e a importância que os estudos gramaticais desempenham frente os estudos funcionalistas e interacionais da linguagem, mas estamos defendendo a ressignificação das estratégias, métodos e táticas de ensino, orientados para atenderem às novas exigências socioeducacionais, a um novo público, à emergência (transformação e evolução) dos gêneros textuais nas mais diversas esferas de circulação e, principalmente, a fim de dinamizarem o ambiente de sala de aula, 
extrapolando a ideia de que o trabalho com o texto deve ser reduzido à produção de redações do Enem, preparando os alunos para tal exame - não desconhecendo a relevância da referida prática textual -, mas refletindo sobre o fato de que o trabalho com texto precisa eleger, segundo Antunes (2017), os pressupostos da textualidade, da intencionalidade, da semanticidade, da comunicabilidade, da interação entre sujeitos que atuam nas relações sociais empreendidas diariamente, em quaisquer contextos.

Assim, é possível afirmar a necessidade de a escola e o Estado reconhecerem independente das relações de poder e de interesse que pode haver na escolha dos livros didáticos, dos módulos escolares e da matriz que rege a distribuição de conteúdos em ambos os manuais - a importância de selecionar ou contemplar determinados conteúdos curriculares e atividades pedagógicas que explorem outros domínios, outras áreas (ANTUNES, 2007), levando em conta aspectos sociodiscursivos, textuais, comunicativos e gramaticais nos mais diversos gêneros e, por que não dizer, privilegiando os usos sociais da fala e da escrita nas práticas de sala de aula, despertando o gosto pela literatura, praticando a leitura e a análise plural e crítica de textos, produzindo gêneros orais e escritos que atendam a propósitos comunicativos variados no mundo e ressaltando a dinamicidade das manifestações linguísticas nos múltiplos contextos sociais (ANTUNES, 2007).

\section{Considerações finais}

Dissertar acerca do imbricamento entre práticas pedagógicas e práticas efetivas sociais de uso da linguagem implica estabelecer a relação entre língua(gem) e sujeito, numa perspectiva dialógica, sociointeracionista, em que se insere um sujeito dialógico, agente, dialético, com autonomia relativa, responsivo ativo, aspectos defendidos pelo Círculo de Bakhtin, tendo em vista que a concepção de linguagem por nós defendida está sob influência de fatores sociais.

Dessa forma, encontramos suporte teórico na Linguística Aplicada, que coloca em evidência a presença de um sujeito inserido em um contexto social, político, ideológico e cultural, atrelado a uma relação de tempo e espaço social. São os aspectos que emanam de tais contextos, manifestos pelos sujeitos da linguagem, os quais permitem refletir acerca 
das identidades de tais sujeitos que constroem sentidos, a partir das relações sociais que estabelecem.

Ademais, a teoria em foco permite dizer que marcas elucidativas de identidade e de relações de poder aparecem na interação entre os sujeitos e são reflexo de escolhas impostas a todo momento por situações que dão forma aos discursos dos sujeitos dialógicos e plurais. Isso significa que não podemos abdicar dessas práticas sociais da linguagem no ensino de língua portuguesa, tampouco propagar discursos, nas orientações ao professor, em livros didáticos, os quais limitem a prática docente.

Nesse sentido, o meio social assume um relevante papel, porque as múltiplas práticas efetivas de linguagem refletem as identidades dos sujeitos em contextos sociocomunicativos diversos, levando em conta fatores externos à língua, os quais devem ser inseridos no processo de ensino e aprendizagem, sobretudo, conforme tratado neste espaço, nas práticas pedagógicas que circundam as aulas de língua portuguesa, elegendo os aspectos sociodiscursivos e ideológicos que fomentam as práticas efetivas de uso da linguagem.

\title{
¿DE GRAMÁTICA A DISCURSO O DE DISCURSO A GRAMÁTICA? IMPLICACIONES DISCURSIVAS PARA LA ENSEÑANZA DE LENGUA PORTUGUESA
}

\begin{abstract}
RESUMEN: Este trabajo tiene como objetivo promover algunas reflexiones no sólo sobre la forma cómo los libros de texto (LD) y los exámenes vestibulares elaboran preguntas relacionadas con diversos contenidos, en particular en el área de la lengua portuguesa, sino también cómo se llevan ciertas informaciones a los estudiantes, a través de textos en los capítulos de LD, y a los profesores que utilizan estos libros, en la sección de orientación al profesor. La arquitectura teórica que apoya esta discusión se basa en la Linguística Aplicada, entremezclándose con otros autores que toman esta dirección teórica, así como la perspectiva sociointeraccionista y discursiva, en la enseñanza de la lengua portuguesa, especialmente cuando abordan la relación entre la enseñanza y el aprendizaje y los aspectos sociodiscisivos de las prácticas del lenguaje. Basamos el debate en un enfoque cualitativo de la investigación (FLICK, 2009), considerando que este enfoque nos permite, como investigadores, la apropiación de métodos y teorías que explican el fenómeno, la observación de perspectivas que sirven de base para el análisis del objeto teórico y la reflexión sobre las cuestiones planteadas. El análisis de estas preguntas e de las orientaciones nos permitió observar que varios libros de texto y exámenes vestibulares, como los que comprendieron este estudio, no abordan las prácticas sociales del lenguaje en la enseñanza de la lengua portuguesa, priorizando sólo los aspectos gramaticales y sin tener en cuenta elementos sociodiscivos importantes, y las orientaciones al profesor no presentan un
\end{abstract}


enfoque sociodiscursivo del lenguaje, que debe tener efecto en el proceso de enseñanza y aprendizaje, en consonancia con los aspectos gramaticales.

PALABRAS CLAVE: Enseñanza de lengua portuguesa; Exámenes vestibulares; Libros de texto; Orientaciones al profesor; Prácticas sociales del lenguaje.

\section{REFERÊNCIAS}

AMARAL, Emília et al. Novas palavras: $2^{\circ}$ ano. 2 ed. São Paulo: FTD, 2013.

ANTUNES, Irandé. Aula de português: encontro \& interação. São Paulo: Parábola, 2003. Muito além da gramática: por um ensino de línguas sem pedras no caminho. São Paulo: Parábola, 2007.

CEREJA, William Roberto; MAGALHÃES, Thereza Cochar; CLETO, Ciley. Interpretação de textos: construindo competências e habilidades em leitura. São Paulo: Atual, 2009.

FABRÍCIO, Branca Falabella. Linguística aplicada como espaço de "desaprendizagem": redescrições em curso. In: MOITA LOPES, Luiz Paulo. Por uma linguistica aplicada Indisciplinar. São Paulo: Parábola, 2006.

FLICK, Uwe. Introdução à pesquisa qualitativa; tradução Joice Elias Costa. 3. Ed. Porto Alegre: Artmed; Bookman, 2009.

MELLO, Sylvia Leser de; FREIRE, Madalena. Relatos da (con)vivência: crianças e mulheres da Vila Helena nas famílias e na escola. Cadernos de Pesquisa, São Paulo (56): 82-105, fev. 1986. Disponível em: < http://publicacoes.fcc.org.br/ojs/index.php/cp/article/view/1355/1354>. Acesso em: 20 abr. 2020.

GERALDI, João Wanderley. A presença do texto na sala de aula. In: LARA, Glaucia Muniz Proença (org.). Lingua (gem), texto, discurso: entre a reflexão e a prática. v. 1. Rio de Janeiro: Lucerna; Belo Horizonte: FALE/UFMG, 2006.

GERALDI, João Wanderley. Concepções de linguagem e ensino de português. In: . O texto na sala de aula: leitura e produção. Cascavel: Assoeste, 1984. p. 41-49.

MOITA LOPES, Luiz Paulo. Afinal, o que é linguística aplicada? In: MOITA LOPES, Luiz Paulo da. Oficina de linguística aplicada: a natureza social e educacional dos processos de ensino/aprendizagem de línguas. Campinas: Mercado das Letras, 1996.

. Discursos de identidade em sala de aula de leitura de L1: a construção da diferença. In: SIGNORINI, Inês. Lingua(gem) e identidade: elementos para uma discussão no campo aplicado. Campinas: Mercado das Letras, 1998.

. Por uma linguística aplicada indisciplinar. São Paulo: Parábola, 2006. 
SANTOS, Lúcia de Fátima; LIMA, Antônio Carlos Santos de. Reflexões sobre letramento e formação de professores de língua portuguesa no ensino a distância. In: FIGUEIREDO, Francisco José de; SIMÕES, Darcilia. Linguistica aplicada, prática de ensino e aprendizagem de linguas. Campinas: Pontes, 2016.

TRAVAGLIA, Luiz Carlos. Gramática e interaşão: uma proposta para o ensino de gramática. 14. ed. São Paulo: Cortez, 2009.

WEFFORT, Madalena Freire. Observação, registro e reflexão: instrumentos metodológicos. 2. ed. São Paulo: Espaço Pedagógico, 1996.

Recebido em: 01/05/2020.

Aprovado em: 03/06/2020. 